\title{
Pattern of Risk Factors and Angiographic Features of Coronary Artery Disease in a Sample of Young Egyptian Patients
}

\author{
Islam Ebeid ${ }^{1}$, Walaa Farid ${ }^{2}$, Ashraf Ahmed ${ }^{1}$, Neveen Samy ${ }^{2}$ \\ ${ }^{1}$ National Heart Institute, Cairo, Egypt \\ ${ }^{2}$ Cardiology Department, Menoufia University, Shebin Elkom, Egypt
}

\section{Email address:}

islamebeid@yahoo.com (I. Ebeid),drwmosa@yahoo.com (W. Farid),dr_ashraf_ahmed@hotmail.com(A. Ahmed), Neveinsami@yahoo.com (N. Samy)

\section{To cite this article:}

Islam Ebeid, Walaa Farid, Ashraf Ahmed, Neveen Samy. Pattern of Risk Factors and Angiographic Features of Coronary Artery Disease in a Sample of Young Egyptian Patients. Cardiology and Cardiovascular Research. Vol. 4, No. 4, 2020, pp. 215-219.

doi: $10.11648 /$ j.ccr.20200404.18

Received: January 9, 2020; Accepted: January 27, 2020; Published: December 16, 2020

\begin{abstract}
Objectives: this study aimed to study the pattern of risk factors \& angiographic features of CAD in young patient aged $<45$ in comparison with older patients in a sample of Egyptian patients. Background: Egypt is one of the developing countries where cardiovascular disease is the leading cause of mortality and morbidity. Purpose of the present study was to assess the risk factors, clinical presentation, angiographic profile including severity of young adults (aged $<45$ years) with coronary artery disease (CAD). Methods: Our study was a prospective, cross sectional study conducted at multicenter hospitals included 300 patients with coronary artery disease ( CAD), group I comprised of one hundred patients aged $<45$ years old and group II comprised of two hundred patients $\geq 45$ years old who underwent coronary angiography at National Heart Institute, Menoufia university hospital from October 2018 to April 2019. Results: Smoking and positive family history were significantly higher in group I with age ( $<45$ years) than group II ( $\geq 45$ years). HTN, DM, obesity were significantly higher in group II with age ( $\geq 45$ years) than group I $(<45$ years). The most common clinical presentation was STEMI were significantly higher in group I than group II \& SCAD was in the second order with significantly higher in group II than in group I. One vessel and two vessel disease were most prominent in group I versus group II while MVD was most prominent in group II versus group I with significant $\mathrm{P}$ value 0.010 . Type $\mathrm{A}$ and $\mathrm{B}$ lesions were the most common types of lesion in group $\mathrm{I}$, while type $\mathrm{C}$ lesion was more common in group II than group I, with significant $\mathrm{P}$ value (0.019). Calcified, bifurcational and ostial lesions were most prominent in group II with highly significant $\mathrm{P}$ value $(<0.001)$ in calcified lesions. Conclusion: Primordial prevention about smoking cessation and life style modification in cutting down obesity will be important epidemiological tool. Awareness on this topic, importance of golden hour and early diagnosis and treatment will have huge economic impact as sizeable number of patients present late.
\end{abstract}

Keywords: Coronary Artery Disease, Risk Factors, Angiography, Young Adults

\section{Introduction}

Coronary artery disease (CAD) is a leading cause of morbidity and mortality in both developing and developed countries [1].

It has been estimated that less than $10 \%$ of all individuals presenting with documented coronary artery disease are under age of 40 years [2].

Young and old patients have different risk factor profiles, clinical presentations, angiographic findings and prognosis [3].

The classic presentation of worsening angina culminating acute coronary syndrome (ACS) is rare in younger patients but the first onset of angina that rapidly progresses to fully evolved myocardial infarction (MI) is often the case [4].

The high prevalence of cardiovascular risk factors " such as:- advanced age, male sex, family history of CAD, hypertension, dyslipidemia, diabetes, smoking and obesity " has been described in the population. The association 
between conventional risk factors and CAD presence is well established [5].

When CAD occurs below 45 years in men, it is called premature coronary artery disease. The risk factors and their relative frequency vary in between the young and older age groups, so did the severity of the disease [6].

Several studies have also suggested that the distribution and relative effects of risk factors, as well as disease presentation may differ across different age group [7].

The most strongly associated risk factor for CHD in young adults is current tobacco use. A recent study of adults $<45$ years of age found an eightfold increase of AMI for those who smoked $>25$ cigarettes/day compared with those who had never smoked [8].

Not only is smoking a risk factor for CHD, but studies of long-term outcomes in young patients found that smoking was a strong predictor of CHD mortality, although this risk declined with smoking cessation [9].

Studies report a wide range of association between CHD in young adults and a positive family history for coronary disease, with estimates varying by age group, population, and specific definition of "family history" [10].

The aim of this work is to study the pattern of risk factors $\&$ angiographic features of CAD in young patient aged $<45$ in comparison with older patients in a sample of Egyptian patients.

\section{Patients and Methods}

Study design:

Our study was a prospective, observational study conducted at two large hospitals included 300 coronary artery disease (CAD) patients at National Heart Institute, Menoufia university hospital from October 2018 to April 2019 divided into two groups to evaluate clinical condition, risk factors and angiographic characteristics, Group (A) Consisted of 100 patients with $\mathrm{CAD}$ aged $<45$ years old, Group (B) Consisted of 200 patients with $\mathrm{CAD}$ aged $\geq 45$ years old to evaluate clinical condition, risk factors and angiographic characteristics. Methods:

All included patients were subjected to complete and detailed medical history, laboratory investigations, resting standard 12 leads electrocardiogram, detection of ejection fraction by echocardiography and coronary angiography.

This study included 300 patients who underwent angiogram at cardiology department of National Heart Institute and cardiology department at Menoufia University Hospital. Coronary angiography considered abnormal when there is diameter stenosis (occlusion) that occurs to one or more of the three major coronary arteries during the angiogram procedure. Significant occlusion defined as equal or more than $50 \%$ narrowing in left main branch and equal or more than $70 \%$ of other epicardial artery [11].

\section{Results}

There were significant difference between Group (A) patients with $\mathrm{CAD}$ aged $<45$ years old, Group (B) patients with $\mathrm{CAD}$ aged $\geq 45$ years old in risk factors as male gender; $73(76 \%)$ vs. $130(63.7 .0 \%), \mathrm{p}=0.033$, body mass index (BMI); $25.2 \pm 3.5$ vs. $27.0 \pm 7.1, \mathrm{p}=0.016$, smoking; 65 (67.7\%) vs $108(52.9 \%) \mathrm{p}=0.061$, hypertension; $40(41.7 \%)$ vs. 112 (54.9\%), $\mathrm{p}=0.032$, diabetes; 22 (22.9\%) vs 89 (43.6\%), $\mathrm{p}=0.001$, dyslipidemia $; 29$ (41.4\%) vs. $22(44.0 \%), \mathrm{p}=0.779$, family history of CAD; $36(37.5 \%)$ vs $51(25.0 \%), \mathrm{p}=0.006$ and were statistically significant between the two groups

Trans thoracic echocardiography (TTE) was undertaken in both treatment arms, The ejection fraction (EF) was similar in both groups; $48.5 \pm 6.5$ in group (A) and $48.8 \pm 7.1$ in group (B), $\mathrm{p}=0.761$.

The most common clinical presentation was STEMI were significantly higher in group I ( $<45$ years) than group II $(\geq$ 45years), SCAD was in the second order with significantly higher in group II ( $\geq 45$ years) than in group I ( $<45$ years). None of SBP or DBP or HR were statistically significant between patients of group A \& patients of group B "table 1".

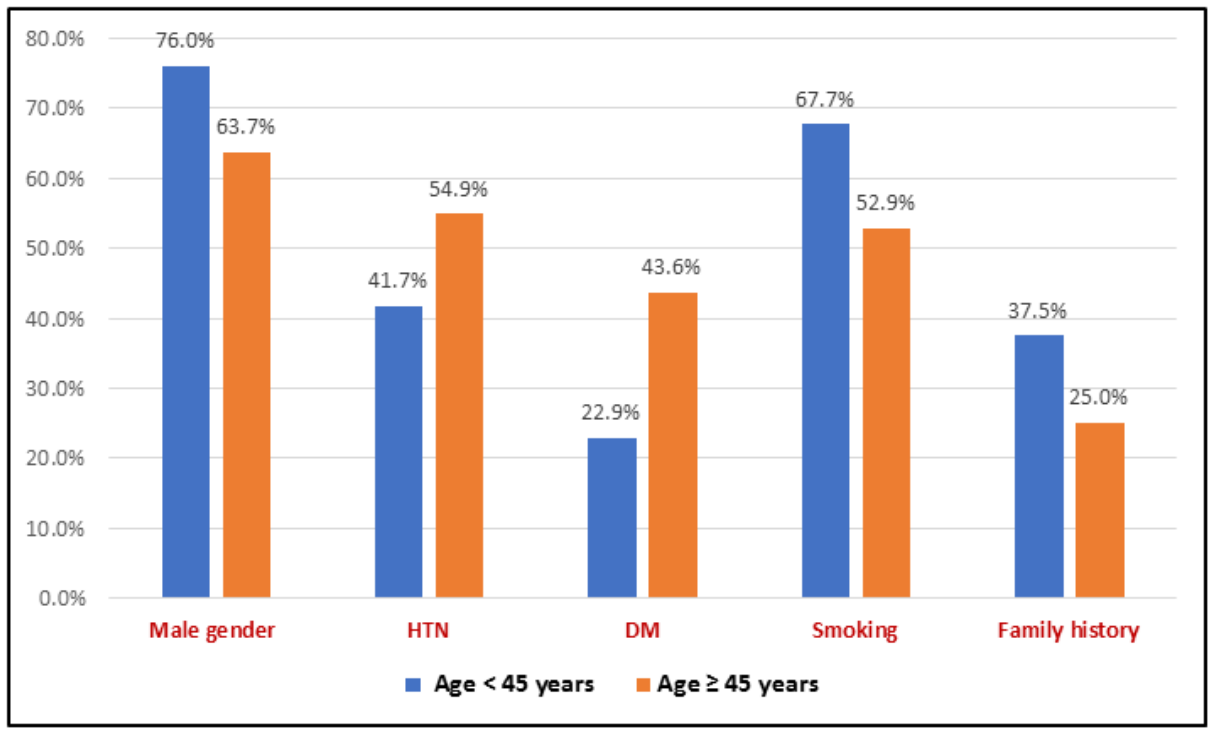

Figure 1. Bar chart between group A and group B regarding the demographic data. 
Table 1. Comparison between the studied groups regarding the clinical data.

\begin{tabular}{llll}
\hline Clinical data & Age $<45$ years & Age $\geq 45$ years & $\begin{array}{l}\text { P-value } \\
\text { (Sig.) }\end{array}$ \\
\hline Count & $\mathbf{9 6}$ & $\mathbf{2 0 4}$ & \\
\hline $\begin{array}{l}\text { Diagnosis } \\
\text { STEMI }\end{array}$ & $60(62.5 \%)$ & $93(45.6 \%)$ & \\
Non-ST ACS & $15(15.6 \%)$ & $46(22.5 \%)$ & $0.012(\mathrm{~S})$ \\
$\begin{array}{l}\text { SCAD } \\
\text { SBP }(\mathrm{mmHg})\end{array}$ & $21(21.9 \%)$ & $65(31.9 \%)$ & \\
$\begin{array}{l}\text { Mean } \pm \text { SD } \\
\text { DBP }(\mathrm{mmHg})\end{array}$ & $123.1 \pm 17.2$ & $118.8 \pm 20.4$ & $0.075(\mathrm{NS})$ \\
Mean \pm SD & $75.2 \pm 10.5$ & $73.7 \pm 11.8$ & $0.294(\mathrm{NS})$ \\
\hline
\end{tabular}

One vessel and two vessel disease were most prominent in group A with age $(<45$ years) versus group B with age $(\geq 45$ years) while MVD was most prominent in group II versus group I with significant $P$ value 0.010 ,

Type A lesion ( discrete $<10 \mathrm{~mm}$ length) and B lesion ( tubular $10-20 \mathrm{~mm}$ length) were the most common types of lesion in group $\mathrm{A}$, while type $\mathrm{C}$ lesion (diffuse excessive tortious $>20 \mathrm{~mm}$ length) was more common in group B than group A, with significant $\mathrm{P}$ value (0.019), Calcified, bifurcational and ostial lesions were most prominent in group $\mathrm{B}$ with highly significant $\mathrm{P}$ value $(<0.001)$ in calcified lesions "table 2".

Table 2. Comparison between the studied groups regarding the coronary angiographic data.

\begin{tabular}{|c|c|c|c|}
\hline $\begin{array}{l}\text { Coronary } \\
\text { angiographic data }\end{array}$ & Age $<45$ years & Age $\geq \mathbf{4 5}$ years & \multirow{2}{*}{$\begin{array}{l}\text { P-value } \\
\text { (Sig.) }\end{array}$} \\
\hline Count & 96 & 204 & \\
\hline \multicolumn{4}{|l|}{ N. of diseased vessels } \\
\hline One vessel & $48(50 \%)$ & $76(37.3 \%)$ & \multirow{3}{*}{$0.010(\mathrm{~S})$} \\
\hline Two vessels & $30(31.3 \%)$ & $62(30.4 \%)$ & \\
\hline Multi-vessels & $18(18.7 \%)$ & $66(32.3 \%)$ & \\
\hline \multicolumn{4}{|l|}{ Lesion type } \\
\hline Type A & $8(8.3 \%)$ & $4(2 \%)$ & \multirow{3}{*}{$0.019(\mathrm{~S})$} \\
\hline Type B & $30(31.3 \%)$ & $56(27.4 \%)$ & \\
\hline Type C & $58(60.4 \%)$ & $144(70.6 \%)$ & \\
\hline \multicolumn{4}{|c|}{ Other lesion characteristics } \\
\hline Calcified & $8(8.3 \%)$ & $58(28.4 \%)$ & $<0.001$ (HS) \\
\hline Bifurcational lesion & $18(18.7 \%)$ & $26(26.7 \%)$ & $0.170(\mathrm{NS})$ \\
\hline Ostial lesion & $14(14.6 \%)$ & $38(18.6 \%)$ & $0.338(\mathrm{NS})$ \\
\hline
\end{tabular}

In STEMI patients; one vessel, two vessel and multivessel disease were most prominent in group I with age $(<45$ years) than in group II with age ( $\geq 45$ years), with no statistically significant difference in both groups. Type A and B lesions were the most common types of lesion in group I, while type $\mathrm{C}$ lesion was more common in group II than group I, with no statistically significant difference in both groups. Calcified lesions was most prominent in group II with significant $\mathrm{P}$ value (0.006). Regarding thrombus grade:- grade 5 was most prominent in group II, but grade 3 and 4 were most prominent in group I. Regarding TIMI flow " preintervention":- TIMI flow 0 was the most prominent in group I “ $<45$ years old "while TIMI I was the most prominent in group II " $\geq 45$ years old " with no statistically significant difference in both groups. Regarding TIMI flow "post- intervention":- TIMI flow 3 was the most prominent in group I " $<45$ years old " to be achieved with no statistically significant difference in both groups "table 3 ".

Table 3. Comparison between the age groups within STEMI patients $(n=153)$ regarding the coronary angiographic data.

\begin{tabular}{|c|c|c|c|}
\hline $\begin{array}{l}\text { Coronary } \\
\text { angiographic data }\end{array}$ & $\begin{array}{l}\text { Age }<45 \\
\text { years }\end{array}$ & Age $\geq \mathbf{4 5}$ years & \multirow{2}{*}{$\begin{array}{l}\text { P-value } \\
\text { (Sig.) }\end{array}$} \\
\hline Count & 60 & 93 & \\
\hline \multicolumn{4}{|l|}{ N. of diseased vessels } \\
\hline One vessel & $33(55 \%)$ & $48(51.6 \%)$ & \multirow{3}{*}{0.645 (NS) } \\
\hline Two vessels & $20(33.3 \%)$ & $29(31.2 \%)$ & \\
\hline Multi-vessels & $7(11.7 \%)$ & $16(17.2 \%)$ & \\
\hline \multicolumn{4}{|l|}{ Lesion type } \\
\hline Type A & $5(8.3 \%)$ & $3(3.3 \%)$ & \multirow{3}{*}{$0.180(\mathrm{NS})$} \\
\hline Type B & $22(36.7 \%)$ & $27(29 \%)$ & \\
\hline Type C & $33(55 \%)$ & $63(67.7 \%)$ & \\
\hline \multicolumn{4}{|c|}{ Other lesion characteristics } \\
\hline Calcified & $4(6.7 \%)$ & $22(23.7 \%)$ & $0.006(\mathrm{~S})$ \\
\hline Bifurcational lesion & $11(18.3 \%)$ & $13(14 \%)$ & 0.470 (NS) \\
\hline Ostial lesion & $11(18.3 \%)$ & $10(10.8 \%)$ & $0.183(\mathrm{NS})$ \\
\hline \multicolumn{4}{|l|}{ Thrombus grade } \\
\hline Grade 1 & $0(0 \%)$ & $1(1.1 \%)$ & \multirow{5}{*}{$0.248(\mathrm{NS})$} \\
\hline Grade 2 & $0(0 \%)$ & $1(1.1 \%)$ & \\
\hline Grade 3 & $8(13.3 \%)$ & $5(5.4 \%)$ & \\
\hline Grade 4 & $24(40 \%)$ & $32(34.3 \%)$ & \\
\hline Grade 5 & $28(46.7 \%)$ & $54(58.1 \%)$ & \\
\hline \multicolumn{4}{|l|}{ TIMI flow pre } \\
\hline TIMI 0 & $37(61.7 \%)$ & $54(58.1 \%)$ & \multirow{4}{*}{$0.774(\mathrm{NS}$} \\
\hline TIMI 1 & $17(28.3 \%)$ & $32(34.3 \%)$ & \\
\hline TIMI 2 & $6(10 \%)$ & $5(5.4 \%)$ & \\
\hline TIMI 3 & $0(0 \%)$ & $2(2.2 \%)$ & \\
\hline \multicolumn{4}{|l|}{ TIMI flow post } \\
\hline TIMI 0 & $0(0 \%)$ & $2(2.2 \%)$ & \multirow{4}{*}{$0.691(\mathrm{NS})$} \\
\hline TIMI 1 & $7(11.7 \%)$ & $7(7.5 \%)$ & \\
\hline TIMI 2 & $2(3.3 \%)$ & $9(9.7 \%)$ & \\
\hline TIMI 3 & $51(85 \%)$ & $75(80.6 \%)$ & \\
\hline
\end{tabular}

\section{Discussion}

Coronary heart disease is the leading cause of morbidity and mortality, worldwide both in developing as well as developed countries, and is responsible for one third or more of all deaths in individuals greater than 35 yearsof age [12].

In Choi J et al 2014, we found that The prevalence of conventional risk factors like hypertension (67\%), dyslipidemia $(67 \%)$, obesity (53\%), smoking (42\%), and diabetes $(33 \%)$ is higher in women with a family history of CAD which is concordant with our study except the gender [13]. In Aggarwal A et al 2014, we found that a recent increase in the prevalence of hypertension [8.86\% (2001$2002)$ to $27.7 \%(2009-2010)]$ and dysglycemia [7.6\% (2001-2002) to $36.15 \%(2009-2010)$ ] in young CAD [14]. In spite of that in Wadkar et al., 2014 systemic hypertension and diabetes mellitus are well established risk factors for atherosclerosis, they may not be prevalent in younger age groups as in older ones, the results were observed with only $14.5 \%$ were diabetic and $19 \%$ were hypertensive in young 
patients [15]. In our study hyper tension and diabetes mellitus were significantly higher in group B with age ( $\geq 45$ years) than group A $(<45$ years). In our study there were $203(67.7 \%)$ male patients, $97(32.3 \%)$ female patients in the study. There were $152(50.7 \%)$ hypertensive patients, $111(37 \%)$ were diabetic, $173(57.7 \%)$ were smoker and 87 $(29 \%)$ had a positive family history of coronary arterial disease.

In Yusuf S et al, 2004 Obesity was the infrequent cause in all the earlier studies with incidence of 3.3\%-20\%. Physical inactivity was present in $53.5 \%$ patients. The prevalence of obesity was $39.1 \%$ in India-AMIYA study which was similar to South Asian cohort of INTERHEART study (44.2\%). In our study, obesity were significantly higher in group B with age ( $\geq 45$ years) than group $\mathrm{A}(<45$ years)

In the study carried by Schoenenberger, 2011 the STEMI presentation was significantly increased in the CAD patients of age $(<45$ years) group while patients of age ( $\geq 45$ years) were presented more by NSTEMI in agreement with, Avezum et al., 2005 \& Al Khadra et al., 2003 who reported that STEMI was more frequent in the young patients, whereas NSTEMI was in the elderly [17]. In our study the most common clinical presentation was STEMI were significantly higher in group I ( $<45$ years) than group II $(\geq$ 45years) while Non-ST ACS and SCAD were significantly higher in group II ( $\geq 45$ years) than in group I ( $<45$ years).

\section{Study Limitations}

First: The present study was not a randomized controlled trial, and a selection bias may have existed.

Second: Small sample size, which reduces the statistical validity of some of the differences between the groups.

Third: Only conventional coronary disease risk factors were identified. Several emerging risk factors such as highSensitivity C- Reactive Protein (hs-CRP), lipoprotein abnormalities, hypercoagulable states, elevated homocysteine levels, markers of inflammation and platelet glycoprotein IIIa, P1A2 polymorphism were not evaluated.

Fourth: Risk-factor identification was based on the information provided by patients or their relatives. Identifying risk factors in this manner leads to an underestimation of their true prevalence; however, this is the method used in recent studies

\section{Conclusion \& Recommendations}

Based on age, CAD patients had a different risk factors profile \& different clinical presentation with variable lesion severity.

STEMI is the most common presentation among the sample of young Egyptian patients which manifests decades earlier compared to Western population. Smoking, family history of premature CAD, obesity were the most common risk factors.

Non ST ACS and SCAD were more in group II " age $\geq 45$ years" with multivessel disease and complication and more prominent in diabetic patients.

Primordial prevention about smoking cessation and life style modification in cutting down obesity will be important epidemiological tool. Awareness on this topic, importance of golden hour and early diagnosis and treatment will have huge economic impact as sizeable number of patients present late.

\section{References}

[1] Roth, Gregory A., et al. The burden of cardiovascular diseases among US states, 1990-2016. JAMA cardiology, 2018, 3.5: 375-389.

[2] Shah, Nadim, et al. Myocardial infarction in the "young": risk factors, presentation, management and prognosis. Heart, Lung and Circulation, 2016, 25.10: 955-960.

[3] Yang, Junjie, et al. Risk Factors and Outcomes of Very Young Adults Who Experience Myocardial Infarction: The Partners YOUNG-MI Registry. The American journal of medicine, 2019; 6: 169-173.

[4] Pradhan, Ravi R., et al. Acute myocardial infarction in a young adult treated successfully with primary percutaneous transluminal coronary angioplasty. European Journal of Biomedical, 2018, 5.1: 799-802.

[5] Vernon, Stephen T., et al. Increasing proportion of ST elevation myocardial infarction patients with coronary atherosclerosis poorly explained by standard modifiable risk factors. European journal of preventive cardiology, 2017, 24.17: 1824-1830.

[6] Gebhard, Catherine, et al. Impact of age and sex on left ventricular function determined by coronary computed tomographic angiography: results from the prospective multicentre CONFIRM study. European Heart JournalCardiovascular Imaging, 2017, 18.9: 990-1000.

[7] R Nakazato, R Arsanjani, et al. Age-related risk of major adverse cardiac event risk and coronary artery disease extent and severity by coronary CT angiography: results from 15187 patients from the International Multisite CONFIRM Study. Eur Heart J Cardiovasc Imaging. 2014 May; 15 (5): 586-594.

[8] Abed, Mona A.; ESHAH, Nidal F.; MOSER, Debra K. Risk profile of myocardial infarction in young versus older adults. Heart \& Lung, 2018, 47.3: 226-230.

[9] Maino, Alberto, et al. Recurrence and mortality in young women with myocardial infarction or ischemic stroke: longterm follow-up of the Risk of Arterial Thrombosis in Relation to Oral Contraceptives (RATIO) study. JAMA internal medicine, 2016, 176.1: 134-136.

[10] Bajaj S, Shamoon F, et al. Acute ST-segment elevation myocardial infarction in young adults: who is at risk? Coron Artery Dis. 2011; 22 (4): 238-44.

[11] Desai, Arpan P.; BHAGARHATTA, Rajeev. Localization of Angina Related Artery By Admission ECG in Unstable Angina and Nstemi Patients. Journal of Hypertension and Cardiology, 2016, 2.1: 10.

[12] Nichols $\mathrm{M}$, Townsend $\mathrm{N}$, et al. Cardiovascular disease in Europe 2014: epidemiological update. Eur Heart J 2014; 35: 2929 [PMID: 25381246. 
[13] Choi J, Daskalopoulou SS, et al. Sex- and gender-related risk factor burdenin patients with premature acute coronary syndrome. Can J Cardiol 2014; 30: 109-117.

[14] Aggarwal A, Aggarwal S, Sharma V. Cardiovascular Risk Factors in Young Patients of Coronary Artery Disease: Differences over a Decade. J Cardiovasc Thorac Res 2014; 6: 169-173.

[15] Wadkar A, Sathe A, et al: Clinical \& angiographic profile of young patients $(<40$ years) with acute coronary syndrome. Journal of indian college of cardiology 2014; 4, 95-100.
[16] Smyth, Andrew, et al. Response by Smyth et al to Letters Regarding Article,"Physical Activity and Anger or Emotional Upset as Triggers of Acute Myocardial Infarction: The INTERHEART Study". Circulation, 2017, 135.10: e644-e645.

[17] Schoenenberger AW, Radovanovic D, et al: Acute coronary syndromes in young patients: presentation, treatment and outcome. Int J Cardiol. 2011; 148 (3): 300-4. 